\title{
Estado, mercado e terceiro setor: A redefinição das regras do jogo
}

The State, the Market and the Third Sector: Redefining the Rules of the Game État, marché et tiers secteur : la redéfinition des règles du jeu

\section{Vasco Almeida}

\section{OpenEdition}

Journals

Edição electrónica

URL: http://journals.openedition.org/rccs/4397

DOI: $10.4000 /$ rccs. 4397

ISSN: 2182-7435

\section{Editora}

Centro de Estudos Sociais da Universidade de Coimbra

Edição impressa

Data de publição: 1 Dezembro 2011

Paginação: 85-104

ISSN: 0254-1106

\section{Refêrencia eletrónica}

Vasco Almeida, «Estado, mercado e terceiro setor: A redefinição das regras do jogo », Revista Crítica de Ciências Sociais [Online], 95 | 2011, colocado online no dia 01 dezembro 2012, criado a 19 abril 2019. URL : http://journals.openedition.org/rccs/4397 ; DOI : 10.4000/rccs.4397 


\title{
VASCO ALMEIDA
}

\section{Estado, mercado e terceiro setor: A redefinição das regras do jogo}

\begin{abstract}
Este artigo parte de uma revisão crítica à teoria dos bens coletivos e à teoria da falha do contrato para mostrar que o terceiro setor não deve ser encarado como um resíduo deixado pelo mercado e pelo Estado, mas sim como uma forma de coordenação da atividade socioeconómica. Tendo como cenário empírico a evolução do terceiro setor em Portugal, pretende-se mostrar que o seu papel crescente na governação se traduziu no aumento da diversidade e da complexidade dos processos socioeconómicos, quer a perspetiva de análise se situe ao nível micro, quer se desloque para o plano macrossocial. Em virtude da sua crescente importância na governação socioeconómica, o terceiro setor tem provocado uma redefinição das regras do jogo e uma transformação da própria lógica de funcionamento do mercado, do Estado e da comunidade.
\end{abstract}

Palavras-chave: Estado; mercado; sistemas socioeconómicos; teoria económica; terceiro setor.

\section{Introdução}

A partir das últimas décadas do século xx, tem vindo a ser dada uma atenção crescente a um conjunto de organizações de caráter associativo, cooperativo ou mutualista, geralmente incluídas no que habitualmente se designa por terceiro setor (Ferreira, 2009a; Almeida, 2011).

$\mathrm{Na}$ Europa e um pouco por todo o mundo, o terceiro setor está fortemente enraizado na história social e económica da generalidade dos países, existindo, por vezes, desde os primórdios da sua fundação. Porém, é o acentuado crescimento que tem conhecido recentemente e a sua atual dimensão que fazem dele um fenómeno ímpar no panorama das sociedades modernas.

É claro que a expressão quantitativa da dimensão e do crescimento do terceiro setor reflete transformações de ordem profunda que se situam ao nível da própria organização e coordenação dos sistemas socioeconómicos. Com efeito, a maior centralidade do terceiro setor nas sociedades e nas economias atuais é, geralmente, explicada através da passagem de governos 
de estrutura hierárquica para formas mais horizontais de governação. Face à mudança, à diferenciação e à complexidade da vida social, a coordenação das economias exige novos processos, mecanismos e atores cujas relações estão constantemente a mudar, assim como as suas fronteiras de atuação. Por consequência, à medida que os processos de coordenação socioeconómica se tornam mais difusos, as organizações do terceiro setor (OTS) surgem como parceiros privilegiados na governação (Almeida, 2011).

É a partir da década de 1970 que começam a surgir algumas teorias económicas preocupadas em explicar a existência de um setor de atividade diferente do mercado e do Estado. ${ }^{1}$ A sua origem é norte-americana e os pressupostos adotados são os da economia neoclássica, o que significa que se assume i) o comportamento racional e maximizador dos agentes com funções de preferências dadas; ii) a ausência de problemas crónicos de informação; iii) a tendência dos sistemas para o estado de equilíbrio; iv) a explicação dos fenómenos sociais através dos comportamentos individuais (Hodgson, 1999: 29; Arnsperger e Varoufakis, 2006: 1-6). As fragilidades deste tipo de análise para o estudo de um setor marcado pela heterogeneidade e pela existência de racionalidades distintas das do mercado são evidentes. Ao terceiro setor foi reservado um lugar residual no sistema económico, sendo a sua existência justificada apenas pelos fracassos institucionais do mercado e do Estado. Porém, esta perspetiva residual está em profundo contraste com a expansão impressionante que o setor tem conhecido nos últimos anos e com o seu papel crescente enquanto mecanismo socioeconómico de governação, com características únicas, uma dinâmica própria e princípios de funcionamento específicos. Há, assim, um profundo desfasamento entre a teoria e a realidade.

Na primeira parte deste artigo, serão analisadas duas das principais abordagens que têm dominado a discussão académica sobre as teorias económicas do setor não lucrativo ${ }^{2}$ - a teoria dos bens públicos e a teoria da falha do contrato. Depois de salientadas as suas principais fragilidades,

\footnotetext{
${ }^{1}$ Os estudos do terceiro setor têm, porém, um importante antecedente histórico que remonta ao século XIX e inícios do século XX. De facto, as suas raízes teóricas encontram-se em autores ligados ao socialismo utópico, como Saint-Simon, Proudhon, Robert Owen, ao social-cristianismo, como Le Play, ou ainda à escola solidária de Charles Gide (ver, a este propósito, Jeantet, 2003).

${ }^{2}$ Existem algumas diferenças entre o conceito de terceiro setor e o de setor não lucrativo, utilizado nas abordagens convencionais pelos autores anglo-saxónicos. A noção de setor não lucrativo põe em relevo a existência de restrições legais e éticas na distribuição dos lucros, excluindo, deste modo, todas as organizações de membros (member-benefit organizations), como as cooperativas e as mutualidades (ver, a este propósito, Almeida, 2011). Por outro lado, o conceito de terceiro setor abrange não só as associações, como também as cooperativas e as mutualidades. Porém, estas diferenças em nada alteram a lógica explicativa do processo de formação de um conjunto de organizações que se situam fora do Estado e do mercado.
} 
defende-se que a compreensão sobre a existência e o papel do terceiro setor nas sociedades contemporâneas exige uma mudança de paradigma que permita contextualizar a sua dinâmica dentro de uma perspetiva plural da governação. ${ }^{3}$ Por fim, através da análise das relações que se estabelecem entre o Estado e as OTS no decorrer do processo de governação, evidencia-se a forma como o terceiro setor tem contribuído, ao nível macro e microssocial, para a reconfiguração institucional dos sistemas socioeconómicos e para uma redefinição das regras do jogo. ${ }^{4}$

\section{As teorias dominantes}

A agenda de investigação do terceiro setor tem-se centrado em três preocupações fundamentais: a problemática da origem (Porque surgem as organizações do terceiro setor?), a problemática do comportamento (Quais os elementos que as distinguem das outras formas de organização?) e a problemática do impacto (Qual a contribuição do setor relativamente a outras formas organizacionais?) (DiMaggio e Anheier, 1990; Enjolras, 1995; Anheier, 1996; 2005). Se bem que esta divisão em três grandes eixos seja, de certa forma, artificial (Almeida, 2011), as teorias económicas têm procurado responder à primeira pergunta, isto é, a sua preocupação tem sido sobretudo a de encontrar as razões explicativas da génese das organizações não lucrativas $(\mathrm{ONL})$. É o caso da teoria dos bens públicos e da teoria da falha do contrato.

\section{A teoria dos bens públicos}

Em 1975, no artigo "Toward a Theory of the Voluntary Nonprofit Sector in a Three-Sector Economy”, Weisbrod desenvolve uma explicação sobre os fatores que determinam quais os bens que serão produzidos pelo Estado, pelo mercado e pelo setor não lucrativo. É a primeira teoria desenvolvida de forma consistente que procura encontrar uma explicação económica para a existência das ONL nas economias contemporâneas. Porém, esta não é a única razão que a torna uma referência obrigatória na literatura sobre o terceiro setor. Sujeita a inúmeras revisões e desenvolvimentos, e sendo talvez a mais citada, a teoria dos bens públicos veio a ter uma influência decisiva sobre as restantes abordagens que surgiram neste campo.

\footnotetext{
${ }^{3}$ Sai fora do âmbito deste artigo a análise da economia social e da economia solidária, pese embora a sua vitalidade empírica e teórica (sobre este assunto cf. Revista Crítica das Ciências Sociais, n. $\left.{ }^{\circ} 84,2009\right)$.

${ }^{4}$ Dentro das correntes institucionalistas na economia, o termo regras do jogo é identificado com o conceito de instituições, sendo estas aqui entendidas como o conjunto de regras, normas, valores, convenções e hábitos que enquadram a vida individual e coletiva.
} 
A análise de Weisbrod (1986 [1975]; 1988) constitui, de certa forma, uma extensão natural das teorias da escolha pública, do teorema do Coase e da teoria da ação coletiva de Olson (Kingma, 2003). Em qualquer das abordagens, as externalidades associadas com a produção de bens públicos são resolvidas através da ação coletiva. ${ }^{5}$ Weisbrod encara as ONL como fornecedoras de bens públicos, ou seja, aqueles bens que se caracterizam pela não exclusividade e pela não rivalidade. ${ }^{6} \mathrm{O}$ Estado, ao satisfazer as necessidades do eleitor médio, deixa de fora o fornecimento de certo tipo de bens públicos (ou quase públicos), dada a heterogeneidade da população. Assim, as ONL surgem para satisfazer uma procura residual que não é coberta nem pela provisão governamental nem pelo mercado. Os pressupostos utilizados, de cariz neoclássico, são os conhecidos. Os agentes comportam-se racionalmente na busca dos seus objetivos individuais de maximização de utilidade; admite-se a existência de determinadas possibilidades de produção e de um dado estado de tecnologia que permitem a produção de bens coletivos e de bens privados de consumo; a utilidade de cada agente é função do consumo de ambos os tipos de bens; as funções de utilidade não são iguais para todos os agentes (Weisbrod, 1986 [1975]: 22).

Como as ONL surgem em consequência da insatisfação de determinados grupos de indivíduos cujas procuras não foram satisfeitas, então a dimensão relativa do setor não lucrativo é função da diversidade de preferências da população. Dito por outras palavras, quanto mais heterogénea for a população, por exemplo em termos religiosos, políticos, étnicos e raciais, maior será o número de ONL.

São vários os estudos que procuram apoiar a tese da heterogeneidade. Por exemplo, a dimensão do setor não lucrativo nos Estados Unidos foi relacionada com a sua diversidade religiosa, política, étnica e racial (Kingma, 2003). O largo trabalho empírico de James (1989) parece também confirmar a teoria. A autora mostra, por exemplo, que, em países desenvolvidos, o peso

\footnotetext{
${ }^{5}$ Nestas abordagens, a noção de ação coletiva está associada ao problema de coordenação das decisões privadas, quando se trata de alcançar um objetivo compartilhado. Buchanan (1965) explica como a ação coletiva através dos clubes é utilizada para o fornecimento de bens públicos. Coase (1960) mostra como é que agentes envolvidos em mercados não eficientes podem negociar, com base em direitos de propriedade definidos pelo Estado, a internalização das externalidades. Por sua vez, Olson (1998 [1965]) examina os custos e benefícios associados com a produção de bens públicos através da ação coletiva dos governos, organizações e famílias.

${ }^{6}$ A não exclusividade implica que não é possível excluir ninguém do seu consumo, pelo menos sem suportar custos elevados. A não rivalidade traduz-se no facto de que o aumento do consumo desse bem por um indivíduo não implica a diminuição da sua quantidade para outros. Porém, apesar do modelo de Weisbrod se referir a bens públicos, a sua teoria aplica-se essencialmente a bens quase-públicos (Anheier, 2005: 121), ou seja, aqueles em que um dos dois critérios utilizados na definição clássica de bens públicos - não exclusividade e não rivalidade - está ausente.
} 
relativo das escolas não lucrativas aumenta em resultado de gostos diferenciados assentes na heterogeneidade cultural. Chang e Tuckman (1996), partindo de um índice que mede a diversidade racial, chegam a conclusões idênticas.

Porém, os resultados empíricos nem sempre são claros. O conhecido estudo internacional de Salamon e Anheier (1998) parece dar consistência à teoria nalguns casos, mas noutros não. A tendência para a dimensão do setor não lucrativo aumentar com a heterogeneidade religiosa dos países não é confirmada em muitos casos, como por exemplo na Bélgica, na Irlanda, em Israel e na República Checa.

No entanto, as críticas mais fortes dirigidas à teoria dos bens públicos situam-se mais ao nível da sua consistência teórica e consequente capacidade explicativa. Em primeiro lugar, uma grande parte dos serviços fornecidos pelas ONL não é constituída por bens públicos. A teoria de Weisbrod foi essencialmente construída a pensar nas ONL cuja porção substancial do seu rendimento assenta nas doações (donation profits), como é o caso da American Heart Association ou da National Cancer Society. Porém, uma parte significativa das ONL produzem bens e serviços não públicos, isto é, são commercial nonprofits, ou seja, aquelas cujo rendimento provém maioritariamente ou exclusivamente da venda de bens e serviços. ${ }^{7}$ A questão é que tem sido este tipo de ONL que mais tem crescido nos últimos anos, como é o caso das creches, dos infantários, dos lares de idosos e dos serviços de apoio domiciliário (Hansman, 1987). Em segundo lugar, para que surjam as ONL, não basta que haja consumidores insatisfeitos. É igualmente necessário que haja um conjunto de interessados (os stakeholders) com preferências idênticas, distintas das do Estado e do mercado (Ben-Ner e Van Hoomissen, 1991). Por último, há ainda outra falha grande na teoria dos bens públicos, frequentemente referida na literatura. As razões pelas quais são as ONL e não as empresas lucrativas a satisfazer a procura de certos bens públicos, face à incapacidade do Estado, não são suficientemente explicadas (Hansman, 1987; Anheier, 2005, Dollery e Wallis, 2003). Aliás, é precisamente daqui que partem as abordagens baseadas nas assimetrias de informação e na confiança, como se irá ver já de seguida.

\section{A teoria da falha do contrato}

Os elementos que antecedem um tipo diferente de abordagem surgem, em 1963, com a publicação de um ensaio de Arrow sobre os cuidados médicos. Arrow (1963) adianta a ideia de que os hospitais não lucrativos podem ser

7 Esta observação aplica-se, principalmente, aos países anglo-saxónicos (Almeida, 2011). 
uma resposta para as assimetrias de informação existentes entre os pacientes e os fornecedores dos referidos cuidados. Mais tarde, em 1973, Nelson e Krashinsky salientaram que a qualidade dos serviços oferecidos nos infantários pode ser difícil de avaliar (Krashinsky, 1986). Sugeriram, então, que os pais das crianças preferem escolher um fornecedor não lucrativo no qual depositem mais confiança, relativamente a um proprietário de uma organização lucrativa, já que este pode tirar vantagens monetárias, através da redução na qualidade dos serviços oferecidos.

No entanto, é com a publicação de um artigo de Hansmann, em 1980, intitulado "The Role of Nonprofit Enterprise”, e com os desenvolvimentos posteriores que o autor lhe deu (Hansmann, 1987), que a teoria da falha do contrato emerge. Uma vez mais, parte-se das premissas convencionais da teoria económica, segundo as quais, em condições normais, os consumidores podem sem esforço ou custo: i) comparar preços e qualidades dos diferentes bens oferecidos, antes da efetivação das suas compras; ii) estabelecer um acordo claro com a empresa escolhida; e iii) determinar, posteriormente, se a empresa cumpriu com o combinado (1986 [1980]: 61). Em resumo, os mercados são transparentes e a informação é perfeita. Ocasionalmente, porém, essas condições podem não ser alcançáveis, quer devido às condições nas quais o produto é comprado, quer devido à própria natureza do bem. Assim, o consumidor não consegue avaliar com rigor a quantidade e a qualidade do bem ou serviço oferecido. Nestas circunstâncias, a competição no mercado pode fazer com que uma empresa lucrativa tenha o incentivo e a oportunidade para se aproveitar dos seus clientes, fornecendo um bem em menor quantidade ou de qualidade mais baixa. É, então, nesta situação, que pode surgir uma ONL (Hansmann, 1987: 29).

Tal como a teoria dos bens públicos, a abordagem de Hansmann exerceu uma larga influência sobre os teóricos do terceiro setor, dando origem a sucessivas revisões e desenvolvimentos. Krashinsky (1986), por exemplo, diferencia os problemas de informação entre consumidores e produtores e aqueles que ocorrem entre os próprios consumidores e tende a ver o aparecimento das ONL como uma forma de economizar nos custos de transação. $\mathrm{Na}$ verdade, não é difícil ver as afinidades entre a sua análise e a abordagem dos custos de transação. Enquanto, na tradição de Williamson (1985), a perspetiva dos custos de transação tende a ver o aparecimento das instituições não mercantis através do grau de incerteza contido nas transações, a teoria de Hansmann foca-se nas características dos bens. ${ }^{8}$ Assim, as conclusões

\footnotetext{
${ }_{8}$ Para uma comparação entre as duas abordagens, ver Badelt (1990).
} 
são idênticas: quando os mercados falham (e as empresas lucrativas, para Hansmann) surgem outras organizações com vantagens comparativas nos custos de transação (Badelt, 1990).

Apesar da teoria da falha do contrato se ter tornado um tema dominante na literatura especializada, tanto a formulação inicial de Hansmann com as formalizações posteriores têm sido alvo de algumas críticas que põem em causa a sua capacidade explicativa.

Antes de mais, repare-se que a consistência da teoria é construída a partir de premissas nunca questionadas por Hansmann. Porém, quando analisadas com algum cuidado perdem toda a sua robustez. Por um lado, a hipótese de que a condição de não distribuição dos lucros oferece uma garantia de proteção ao consumidor contra comportamentos oportunistas é, sem dúvida, exagerada (Bacchiega e Borzaga, 2003). Há uma grande variedade de estudos mostrando que, frequentemente, os interesses de diretores, gestores e empregados não estão alinhados com os interesses da organização. ${ }^{9}$ Por outro lado, a teoria repousa igualmente na assunção de que as empresas lucrativas que concorrem nos mesmos setores económicos das ONL não têm interesse em construir uma reputação de não exploração dos consumidores. Ora, tem sido demonstrado que, quando existem fluxos de informação fortes entre vendedores e consumidores em transações que se repetem ao longo do tempo, as consequências de um comportamento não cooperativo levam os produtores a ter interesse na construção de uma reputação que inspire confiança aos consumidores (Kingma, 2003: 84-85).

Outro reparo que se pode apontar à teoria é o seu simplismo ao supor que indivíduos que, na realidade, são produtores de bens ou serviços ou consumidores com interesses diferentes estejam sempre em condições de negociar sobre os vários arranjos contratuais. Assume-se que o processo de escolha institucional se desenvolve num contexto de mercado livre que tende para soluções de equilíbrio, mas não se explica se é o produtor, o consumidor ou ambos que escolhem o tipo de forma organizacional. Assim, tem todo o sentido perguntar, como faz Badelt (1990: 62), se, por exemplo, os doentes têm ou não alguma escolha sobre o tipo de serviço hospitalar oferecido ou se são os políticos ou eleitores que decidem sobre qual o tipo de forma organizacional que fornece, por exemplo, os serviços de transporte.

Estelle James (1987) chama, ainda, a atenção para o facto de a não distribuição de lucros não ter um peso correspondente nos sistemas legais e fiscais da maioria dos países. Assim, essa cláusula pode ser ultrapassada pelas ONL através da subsidiação cruzada de atividades. Por exemplo, os

${ }_{9}$ A este respeito ver, por exemplo, Ortmann e Schlesinger (2003: 82). 
excedentes de uma atividade podem ser afetados para cobrir os deficits de outras atividades, o que significa que, na verdade, pode haver uma distribuição indireta de lucros.

Por último, mas não menos importante, note-se que os argumentos teóricos estão exclusivamente centrados no lado da procura. Tal como na teoria dos bens públicos, os incentivos que levam os agentes a formarem uma ONL são ignorados.

\section{Uma visão plural de governação}

Apesar dos reparos que são feitos às duas abordagens analisadas, não deixa de ser relevante observar que a insatisfação parte de dentro, isto é, as críticas são feitas dentro das fronteiras do paradigma convencional, o que explica, pelo menos parcialmente, um segundo aspeto não menos notável. É que, para além do caráter reconhecidamente limitado das teorias, nunca é realmente questionado aquilo que parece estar em causa: os próprios limites metodológicos do programa de investigação adotado (Almeida, 2005). De facto, as críticas situam-se mais ao nível da sua consistência interna e do seu caráter explicativo. ${ }^{10}$ Mesmo nas raras vezes em que são colocadas algumas interrogações sobre a validade das suas premissas (Nyssens, 2000) isso não parece ser suficiente para deslocar o enfoque analítico para além das fronteiras da economia ortodoxa. Porém, parece evidente que são precisamente os fundamentos metodológicos das teorias, nomeadamente, o individualismo metodológico e o pressuposto da racionalidade maximizadora, que conduziram a uma perspetiva reducionista dos processos socioeconómicos. ${ }^{11}$

Como se viu, um dos pontos comuns que une as teorias económicas analisadas é, sem dúvida, o facto de encararem o setor não lucrativo de forma residual, como algo que resulta da motivação, dos incentivos e das racionalidades individuais. De um modo ou de outro, todas elas acabam por ver a génese das ONL como um subproduto resultante das falhas do mercado e do Estado. A teoria dos bens públicos de Weisbrod estabelece um modelo para a ação não lucrativa baseada nas falhas do Estado, ao passo que a teoria da falha do contrato de Hansmann assenta nas falhas do mercado. De facto, para ambas as teorias a governação, trata-se apenas de

\footnotetext{
${ }^{10}$ Uma análise completa das principais críticas pode ser encontrada em Anheier e Ben-Ner (2003), Anheier (2005) e Dollery e Wallis (2003) e, de forma mais resumida, em Bacchiega e Borzaga (2003), Rose-Ackerman (1986), James (1990) e Badelt (1990). Porém, a obra de Anheier e Ben-Ner (2003) reveste-se de particular interesse, pois combina alguns capítulos críticos com a perspetiva e resposta de alguns dos autores das respetivas teorias.

${ }^{11}$ Para uma explicação mais detalhada sobre a forma como o individualismo metodológico e o pressuposto da racionalidade maximizadora levaram a uma visão limitada do papel do terceiro setor nas sociedades contemporâneas, ver Almeida (2011).
} 
um problema de combinar mais ou menos mercado com mais ou menos Estado, e só perante os fracassos institucionais de ambos surge o setor não lucrativo. É, pois, uma visão pobre de governação que tem dominado a teoria económica.

Esta perspetiva redutora e limitada dos processos socioeconómicos é, desde há muito, contrariada pela corrente do designado velho institucionalismo, dominante nas primeiras décadas do século xx. Desde aí, a corrente institucionalista tem evoluído em diversos sentidos, sendo difícil apresentá-la, hoje em dia, como um campo de conhecimentos homogéneo (Reis, 2007: 15-16). Apesar da sua enorme diversidade, a ideia central comum nas abordagens institucionalistas é a de que as instituições, isto é, as regras, as normas, os valores, as convenções e os hábitos, estruturam o comportamento dos indivíduos e organizam as dinâmicas dos sistemas sociais, materializando-se em determinadas configurações sociais e políticas que diferenciam as economias. Como as instituições são o resultado das interações entre indivíduos que, através de conflitos e consensos, procedem à sua criação, elas revelam a capacidade de decisão e a intencionalidade dos agentes, em vez de os reduzirem a meros calculadores da maximização das suas funções de preferências. Assim, com a noção de instituições, a economia é concebida "como algo que é inerente aos indivíduos e aos actores coletivos - resulta da sua acção - e não como algo que lhes é estranho e os submete" (Reis, 2007: 7). A noção de instituições remete, ainda, para a ideia de diversidade, pois os valores, os hábitos e as regras que se materializam em configurações institucionais estão dependentes da complexidade dos processos históricos, dos contextos sociais e das culturas. As economias estruturam-se de forma diversa através de articulações específicas e complementaridades que ligam os diferentes setores institucionais.

Uma visão bipolar Estado/mercado da coordenação económica é substituída por uma perspetiva plural da governação, já que nela participam "várias estruturas, vários actores, vários processos, várias capacidades, vários vocabulários e, sobretudo, vários mecanismos" (ibidem: 39). Esses mecanismos, para além do Estado e do mercado, são também as hierarquias empresariais, as redes, as comunidades e as associações (Hollingsworth e Boyer, 1997) ou, dito de forma mais ampla, o terceiro setor. O Estado regula os outros mecanismos de coordenação e estabelece os direitos de propriedade, podendo ser, ao mesmo tempo, um ator económico; no mercado procede-se à troca de bens e serviços através do mecanismo dos preços; as hierarquias empresariais suprimem o mecanismo de mercado, internalizando determinadas transações que passam a ser coordenadas por uma autoridade; as redes estabelecem formas de organização de atores e de processos 
heterogéneos, como, por exemplo, aquelas que se formam entre empresas e universidades; as comunidades, frequentemente organizadas segundo o princípio da reciprocidade, unem agentes sociais e territórios; o terceiro setor fornece determinado tipo de bens e serviços sociais, através de uma lógica solidária, muitas vezes em regime de contratualização com o Estado. Em resumo, as economias devem ser encaradas como configurações institucionais complexas, governadas por diferentes mecanismos de coordenação, onde participam diversos atores portadores de diferentes racionalidades.

Uma perspetiva institucionalista das dinâmicas socioeconómicas conduz, assim, a uma visão muito diversa do terceiro setor do que aquela que é fornecida pelas teorias económicas analisadas. $\mathrm{Na}$ verdade, ele é, antes de mais, uma forma de coordenação da atividade económica e social, dentro da configuração institucional das sociedades contemporâneas. Por esse motivo, a sua existência deve ser explicada através das interdependências e das articulações que mantém com os restantes setores institucionais da economia.

Por outro lado, também os processos que deram origem às OTS, as dinâmicas de funcionamento que as caracterizam, bem como o impacto social e económico que têm na sociedade, dependem das especificidades próprias que marcam as configurações institucionais onde estão embutidas. As economias são o produto de um longo processo histórico que deu origem a diferentes compromissos institucionalizados traduzidos em articulações específicas e complementaridades diversas, que diferenciam as sociedades contemporâneas. Daí a enorme diversidade que o terceiro setor apresenta a nível internacional. As associações de expressão política e de defesa de causas na Suécia, as organizações de habitação social no Reino Unido, as empresas sociais italianas, as mutualidades francesas e as Instituições Particulares de Solidariedade Social (IPSS) em Portugal conheceram lógicas diferentes na sua génese, funcionamentos distintos que se materializam, por exemplo, em diferentes formas de se relacionarem com o Estado e com os restantes setores da sociedade e da economia.

Neste aspeto, as abordagens europeias do terceiro setor foram um pouco mais longe do que as perspetivas norte-americanas presentes nas duas teorias atrás analisadas. De facto, ao invés de explicarem as dimensões económicas de um setor através dos conceitos e dos instrumentos das teorias dos mercados, seguiram uma abordagem de caráter mais sociológico cujo objetivo principal foi o de explicar as particularidades de um terceiro setor como parte de um conjunto plural de economias, colocando a tónica na sua natureza aberta, mista e intermediária. A grande vantagem em relação às abordagens norte-americanas é que se faz notar que a especificidade do setor está relacionada com o quadro institucional dentro do qual operam 
as organizações, "contrabalançando e entrelaçando diferentes princípios económicos" (Evers e Laville, 2004: 36). Porém, o grande problema reside na dificuldade em distinguir uma lógica própria de funcionamento do terceiro setor e, por consequência, em identificar o seu papel específico como mecanismo de governação económica.

Um bom exemplo disto é o conhecido triângulo de Evers (ver Figura 1), frequentemente invocado e geralmente aceite como um instrumento adequado para situar o lugar estrutural do terceiro setor. O espaço vazio, delimitado pelos três vértices de um triângulo que representam o Estado, o mercado e a comunidade, seria ocupado pelo terceiro setor. Segundo Evers, o terceiro setor surge como uma dimensão do espaço público nas sociedades civis, isto é, ele deve ser visto mais como uma área intermédia e não propriamente como um setor definido de forma clara (1995: 159). As noções de espaço público e de sociedade civil, utilizadas pelo autor, sugerem que as democracias modernas desenvolveram uma área social caracterizada pela associação não coerciva, pela representação dos interesses políticos e sociais, pela solidariedade, pela ajuda e pela autoajuda (Evers, 1995: 161).

FIGURA 1 - O Triângulo de Evers

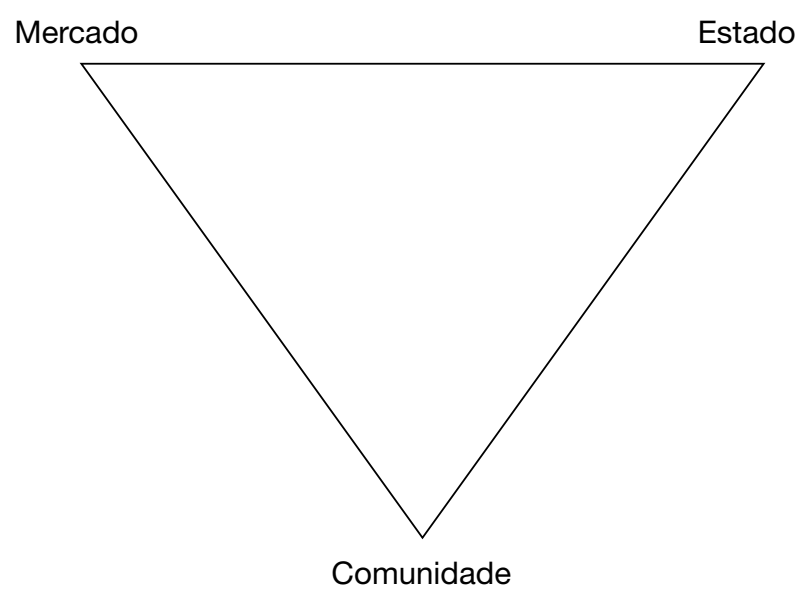

Fonte: Evers, 1995

Observa-se assim que a análise de Evers também não ajuda a eliminar a ideia residual e vaga do terceiro setor como algo que não é Estado, não é mercado e não é comunidade. No entanto, como se mostrará na secção seguinte, há sinais muito claros sobre a forma única como o terceiro setor tem desempenhado um papel crescente na definição das regras do jogo, seja pela influência nas alterações do quadro legal, do sistema fiscal ou na 
definição das políticas, seja pela influência na própria lógica de funcionamento do mercado, do Estado e da comunidade. É por isso que uma compreensão mais clara do terceiro setor tem que ter em conta todo um processo histórico, dinâmico e complexo que, por variadas razões, o tem empurrado para um lugar central na governação das sociedades contemporâneas. Pondo a questão noutros termos, o terceiro setor não pode ser apenas situado no triângulo entre o Estado, o mercado e a comunidade, não só porque possui uma lógica única de funcionamento com atores, processos e quadros cognitivos próprios, mas também porque é um dos nós da configuração institucional das economias. Este aspeto torna-se bastante claro quando se analisam, por exemplo, as relações entre o Estado e o terceiro setor, tendo como ilustração empírica o caso português.

\section{Governação, Estado e terceiro setor}

A ideia de governação pretende chamar a atenção para a participação de um conjunto alargado de atores nos processos de coordenação dos sistemas socioeconómicos. A transição das formas mais tradicionais de governação hierárquica para a governação em rede é vista, por muitos autores, como o resultado das próprias transformações do Estado. Assim, em virtude da crescente complexidade e diferenciação dos processos sociais, o Estado tem optado por associar, na execução e coordenação das suas políticas, novos atores como, por exemplo, o terceiro setor. Entende-se, assim, que muitos autores procurem compreender o aparecimento de novas formas de governação a partir das mudanças que têm afetado os Estados contemporâneos. Esta centralidade teórica do Estado na explicação dos novos processos de governação pode ser também justificada pelo seu duplo papel. De facto, se, por um lado, o Estado é um parceiro igual na governação, por outro é, ao mesmo tempo, o organizador das condições de governação (Ferreira, 2009b), pois a ele compete a definição dos dispositivos reguladores.

Embora não seja possível negar a importância do Estado na definição das regras do jogo da governação, a sua centralidade teórica tende a fazer esquecer o papel dos outros atores sociais, colocando-os como mero recetáculo das políticas estabelecidas pelos atores públicos e dos papéis que aquele lhes atribui. Esta visão limitada da governação é facilmente contrariada pela realidade, como o caso português bem o elucida.

As OTS têm vindo a desempenhar um papel crescente na governação societal, em Portugal, designadamente na provisão de bens e serviços sociais destinados, por exemplo, à prevenção de grupos de risco, à diminuição da exclusão social ou à regeneração urbana. Isso pressupôs a criação de um 
conjunto de dispositivos institucionais, desde aqueles que enquadram de forma mais geral a atividade das OTS, como a Constituição ou a Lei de Bases da Segurança Social, até aos mais específicos, como o Estatuto das IPSS que define os seus objetivos ou os despachos normativos que organizam as relações com o Estado. Sendo certo que estas regras do jogo são, em última instância, aprovadas pelos poderes públicos, a sua definição está bem longe de se poder considerar o resultado de um processo unilateral. $\mathrm{Na}$ verdade, muito do quadro regulador do terceiro setor foi estabelecido através de negociações, nas quais a capacidade de pressão das confederações que representam o terceiro setor em Portugal parece ter sido decisiva na redação final dos diplomas (Almeida, 2011).

Assim, a governação nas sociedades contemporâneas não pode ser entendida somente como a consequência de uma mera transferência de funções do Estado, mas também como uma renegociação dos papéis desempenhados pelos vários atores sociais. Por outro lado, pode afirmar-se que a hierarquia dos setores institucionais (por exemplo, Estado, terceiro setor e mercado) determina os resultados do processo de criação das regras formais. Assim, quanto mais dominante se torna um setor institucional, maiores são as possibilidades de impor a sua lógica ao conjunto da arquitetura institucional do sistema socioeconómico (Amable, 2005).

No caso do terceiro setor, as novas tendências nos processos de governação têm constituído uma oportunidade para a sua afirmação enquanto ator político e económico. Um exemplo particularmente elucidativo reside na questão do financiamento público às IPSS, que, a partir do início da década de 1990, passa a ser enquadrado pelos protocolos de cooperação, celebrados anualmente entre o governo, através de um dos seus membros, e as uniões representativas das IPSS, nomeadamente a União das Instituições de Solidariedade (UIPSS), ${ }^{12}$ a União das Misericórdias Portuguesas (UMP) e a União das Mutualidades (UM).

O aparecimento dos protocolos de cooperação, mais do que uma alteração de regime de financiamento, representa uma mudança de paradigma nas relações de contratualização entre Estado e IPSS. Com efeito, o protocolo de cooperação é um instrumento jurídico que define as normas de enquadramento daquelas relações, bem como algumas linhas orientadoras das políticas sociais. Resultando de uma reivindicação da UIPSS, numa fase em que a sua capacidade negocial era já forte, o seu aparecimento inicia um período de maior estabilidade no relacionamento entre a administração pública e as IPSS, marcado pela "corresponsabilização solidária do

$\overline{12}$ Mais tarde, veio a dar origem à Confederação Nacional das Instituições de Solidariedade (CNIS). 
Estado", pela "afirmação da natureza particular ... e pelo reconhecimento da idoneidade" das instituições (Ministério do Emprego e da Segurança Social, 1992).

Desde a data da assinatura do primeiro protocolo de cooperação, em 1992, nota-se que os seus objetivos, para além de instrumentais, são também programáticos, pois aí se definem orientações, metodologias e prioridades no domínio da cooperação entre os centros distritais de segurança social e as IPSS. Por exemplo, apontam-se novas orientações nos modelos de cooperação (nomeadamente, a intenção de se avançar com o financiamento direto às famílias, expressa no protocolo de 2006) ou definem-se mesmo novos modelos de cooperação, como o modelo de diferenciação positiva, previsto no protocolo de 2007. Incentivam-se, igualmente, novas formas de cooperação (o caso dos acordos de intervenção comunitária), asseguram-se condições de acesso a programas e projetos nacionais e internacionais e definem-se prioridades como a aposta na qualificação das respostas sociais.

Porém, a importância do papel do terceiro setor como ator político não se esgota na definição das regras da cooperação com o Estado, tal como o comprova a presença das uniões e confederações que representam o setor nas mais variadas instâncias de governação em Portugal, designadamente nas áreas ligadas às políticas sociais e à ação social. ${ }^{13}$

Note-se, ainda, que a influência do terceiro setor na definição das regras do jogo, ou seja, o seu papel enquanto ator político, determina as suas funções como ator económico. A crescente importância das OTS na produção de determinadas respostas sociais, por exemplo, nas áreas da população idosa, da infância e juventude ou da família e comunidade, não podem ser vistas como uma mera delegação de competências do Estado no terceiro setor, mas também como a consequência dos interesses manifestados pelas organizações representativas deste em assumir a produção em alguns setores de atividade económica. Assim, como se verá de seguida, o papel das OTS nos processos de governação não deve apenas ser visto a um nível macrossocial, como também no plano microssocial, através da sua incrustação nos sistemas sociais de produção locais.

\footnotetext{
${ }_{13}$ Por exemplo, o papel negociador das IPSS tem estado bem presente no Conselho Económico e Social, no Pacto de Cooperação para a Solidariedade Social, na Comissão do Mercado Social de Emprego, na Comissão do Rendimento Social de Inserção, na Comissão Nacional de Proteção de Crianças e Jovens em Risco e no Conselho Consultivo do Instituto da Segurança Social, participando, ainda, em vários organismos ministeriais, em áreas tão diversas como a toxicodependência, pessoas com deficiência e imigração (Ferreira, 2005).
} 


\section{O terceiro setor na governação local}

Alguns estudos empíricos mostram que a contribuição das OTS na provisão de bens e serviços e nos mercados de trabalho locais é deveras significativa. No que respeita à provisão de bens e serviços, constata-se que em Portugal cerca de $70 \%$ das respostas sociais na área da ação social são fornecidas, ao nível local, pelas OTS, em particular pelas IPSS (Almeida, 2011). Por exemplo, em inúmeras freguesias as IPSS são mesmo as únicas organizações que oferecem determinadas respostas sociais, como por exemplo creches, infantários, centros de atividades de tempos livres (CATLs), centros de dia, apoio domiciliário e lares para idosos. Acrescente-se ainda que a dimensão das suas despesas ou das receitas é muitas vezes superior ao volume médio de negócios das empresas dos concelhos onde estão localizadas (Almeida, 2011).

Por outro lado, as OTS, ao produzirem bens e serviços, empregam pessoas, tal como uma empresa capitalista ou um organismo público e, já que a sua produção é, de uma forma geral, de natureza trabalho-intensiva, o seu potencial de criação de emprego tende a ser elevado. Uma vez mais, os estudos empíricos mostram que as OTS constituem importantes fontes de criação de emprego, sendo frequentemente as maiores empregadoras locais (ibidem). Atente-se ainda nos efeitos indiretos sobre a criação de emprego. Em primeiro lugar, uma parte do salário dos funcionários das OTS é gasto em bens e serviços locais gerando, por esta via, efeitos de repercussão indiretos no estímulo ao emprego. Em segundo lugar, a produção de bens e serviços facilita o acesso ao emprego por parte de certos grupos de indivíduos. A existência de um centro de dia, do apoio domiciliário ou de um lar possibilita uma maior procura de emprego para os parentes que cuidam dos idosos, tal como a existência de creches ou de CATLs abre oportunidades de procura de emprego para os pais das crianças, particularmente para as mulheres. Em terceiro lugar, a dinamização do emprego ocorre através dos inputs necessários à produção dos serviços oferecidos. A grande parte das mercadorias consumidas e dos fornecimentos e serviços externos, como géneros alimentares, produtos farmacêuticos, obras de construção e reparação, é adquirida localmente (ibidem).

Além de serem um elemento fundamental na ativação das economias locais, as OTS constituem igualmente um polo dinamizador da vida social de comunidade. Por um lado, isto deve-se ao facto de um dos traços distintivos das OTS residir, precisamente, na sua capacidade de produzir diferentes tipos de interações que podem ser designadas por ativos relacionais (OECD, 2003: 11). A pertinência do conceito deriva da constatação de que há relações sociais e económicas nas quais a identidade, a atitude e 
as motivações das pessoas envolvidas são elementos essenciais na criação e no valor dos ativos. Por outro lado, como a diversidade das respostas sociais oferecidas pelas OTS ao nível local abrange uma parte significativa da população, designadamente as crianças e os jovens que frequentam a creche, o pré-escolar e os CATLs (o que necessariamente acaba por envolver os pais), e os idosos do centro de dia, apoio domiciliário e lar, daí resulta uma densificação das interações sociais. ${ }^{14}$ Este processo de densificação das interações pode ocorrer ao nível dos processos primários da vida quotidiana, podendo traduzir-se na constituição de relações sociais semiformalizadas ou na formação de interações mais formalizadas e organizadas (Kooiman, 2003).

Em síntese, ao nível microssocial, as OTS revelam capacidade de reconfiguração das relações entre os agentes sociais locais e, ao estabelecerem novos fluxos económicos e novas redes de envolvimento cívico, constituem-se como parceiros centrais nos processos de governação local.

\section{Considerações finais}

A análise do processo de criação das regras e das normas que coordenam as relações de contratualização entre as IPSS e o Estado, ainda que breve, mostrou que a construção do quadro regulador é consequência de uma relação de forças entre diferentes atores. Dito de outro modo, as instituições, principalmente as que são definidas no plano formal, traduzem um compromisso político entre atores diferenciados. Por isso é que a noção de hierarquia institucional se revela essencial para entender não só o papel que os diversos atores ocupam na governação societal, como também o próprio processo de mudança institucional. De facto, as instituições não emergem espontaneamente através da interação voluntária entre agentes económicos que procuram maximizar a sua satisfação, mas sim através de um processo político que envolve um equilíbrio de forças entre interesses heterogéneos.

É importante ainda acrescentar que a dinâmica do terceiro setor na governação se traduziu no aumento da diversidade e da complexidade dos processos socioeconómicos. Esta observação pode ser confirmada quer a perspetiva de análise se situe ao nível micro, quer se desloque para o plano macrossocial.

A participação do terceiro setor na governação, no plano microssocial, trouxe consigo uma densificação das interações estabelecidas entre os mais diversos agentes sociais, sejam eles atores individuais ou organizações. Por

\footnotetext{
${ }^{14}$ No âmbito de um estudo empírico (Almeida, 2011), uma funcionária de uma IPSS afirmava numa entrevista que "não há nenhuma família nesta freguesia que não tenha alguém ligado à [nossa] associação”.
} 
outro lado, a densificação das interações foi acompanhada, também, por uma intensificação e por uma diversificação dos fluxos económicos, através de novas formas de organização de produção de bens e serviços e de criação de emprego.

Ao nível macrossocial, é a própria configuração institucional das economias que se transforma, em virtude da crescente importância do terceiro setor na governação socioeconómica. Surgem novas regras, normas, hábitos e valores que dão um enquadramento diferente à vida económica e social. Tudo isto implicou uma redefinição do sistema legislativo e das relações de contratualização entre Estado e terceiro setor, assim como a alteração das relações entre os demais setores institucionais da economia, por exemplo, entre o mercado e o terceiro setor. Por outro lado, as dinâmicas sociais tornam-se mais diversas e multifacetadas, à medida que o terceiro setor vai ganhado um lugar proeminente na coordenação económica. Naturalmente que todas estas alterações modificaram a distribuição e a afetação de recursos económicos, não só em Portugal como na generalidade dos países. Assim, uma parte cada vez mais significativa das transações ocorre através de arranjos institucionais que se situam fora do mercado. Seja ao nível da produção de bens e serviços seja ao nível do emprego, o terceiro setor torna-se uma força económica maior.

Em resumo, reforça-se assim a ideia-chave defendida ao longo deste texto: o terceiro setor é um elemento central na estrutura de governação das sociedades contemporâneas e não um mero subproduto que resulta das falhas do mercado e do Estado. Esta questão remete, então, para a necessidade de substituir as análises económicas convencionais por uma visão plural da governação que dê conta do lugar do terceiro setor enquanto um dos nós da configuração institucional dos sistemas socioeconómicos.

\section{Referências bibliográficas}

Almeida, Vasco (2005), "A lógica socioeconómica do terceiro sector", Interações, 8 , 55-81.

Almeida, Vasco (2011), As Instituições Particulares de Solidariedade Social. Governação e terceiro sector. Coimbra: Editora Almedina.

Amable, Bruno (2005), Les cinq capitalismes. Diversité des systèmes économiques et sociaux dans la mondialisation. Paris: Éditions du Seuil.

Anheier, Helmut (1996), "Pour une révision des théories économiques sans but lucrative”, Problémes Économiques, 2456, 28-32.

Anheier, Helmut (2005), Nonprofit Organizations. Theory, Management, Policy. London/ New York: Routledge. 
Anheier, Helmut; Ben-Ner, Avner (orgs.) (2003), The Study of the Nonprofit Enterprise. Theories and Approaches. New York: Kluwer Academic/Plenum Publishers.

Arnsperger, Christian; Varoufakis, Yanis (2006), "What is Neoclassical Economics?", Post-Autistic Economics Review, 38, 2-12.

Arrow, Kenneth (1963), "Uncertainty and the Welfare Economics of Medical Care”, American Economic Review, LIII(5), 941-973.

Bacchiega, Alberto; Borzaga, Carlo (2003), "The Economics of the Third Sector: Toward a More Comprehensive Approach”, in Helmut Anheier; Avner Ben-Ner (orgs.), The Study of the Nonprofit Enterprise. New York: Kluwer Academic/Plenum Publishers, 27-48.

Badelt, Christoph (1990), "Institutional Choice and the Nonprofit Sector", in Helmut Anheier; Wolfgang Seibel (orgs.), The Third Sector: Comparative Studies of Nonprofit Organizations. Berlin/New York: Walter de Gruyter, 53-63.

Ben-Ner, Avner; Van Hoomissen, T. (1991), "Nonprofits in the Mixed Economy: A Demand and Supply Analysis", Annals of Public and Cooperative Economics, 62, 519-550.

Buchanan, James (1965), “An Economic Theory of Clubs”, Economica, 32, 1-4.

Chang, Cyril; Tuckman, Howard (1996), "The Goods Produced by Nonprofit Organizations”, Public Finance Review, 24(1), 25- 43.

Coase, Ronald (1960), "The Problem of Social Cost", Journal of Law and Economics, 3(1), 1-44.

DiMaggio, Paul; Anheier, Helmut (1990), “The Sociology of Nonprofit Organizations and Sectors”, Annual Review of Sociology, 16, 137-159.

Dollery, Brian; Wallis, Joe (2003), The Political Economy of the Voluntary Sector. A Reappraisal of the Comparative Institutional Advantage of Voluntary Organisations. Cheltenham/Northampton: Edward Elgar.

Enjolras, Bernard (1995), “Comment Expliquer la Présence D’Organisations à But Non Lucratif dans une Économie de Marché? Une théorie socio-économique des organisations non lucratives", Annals of Public and Cooperative Economics, 66(4), 431-456.

Evers, Adalbert (1995), "Part of the Welfare Mix: The Third Sector as an Intermediate Area”, Voluntas, 6(2), 119-139.

Evers, Adalbert; Laville, Jean-Louis (2004), The Third Sector in Europe. Cheltenham/ Northampton: Edward Elgar.

Ferreira, Sílvia (2005), "The Places of the Third Sector in the Portuguese Welfare Regime: The Case of Social and Family Services". Comunicação apresentada na Primeira Conferência Europeia EMES/ISTR, "Concepts of the Third Sector, The European Debate: Civil Society, Voluntary Organizations, Social and Solidarity-Based Economy", Paris, 27 a 29 de abril.

Ferreira, Sílvia (2009a), "A invenção estratégica do terceiro sector como estrutura de observação mútua: uma abordagem histórico-conceptual”, Revista Crítica das Ciências Sociais, 84, 169-192. 
Ferreira, Sílvia (2009b), "Complexidade na governação do bem-estar e redefinição das fronteiras do espaço público não estatal”. Comunicação apresentada no X Congresso Luso-Afro-Brasileiro, Universidade do Minho, Braga, 6 de fevereiro.

Hansmann, Henry (1986), "The Role of Nonprofit Enterprise”, Yale Law Journal, 89(5), 103-127 [1. a ed.: 1980]. Reimpresso em Susan Rose-Ackerman (org.), The Economics of Nonprofit Organizations: Studies in Structure and Policy. New York: Oxford University Press, 57-84.

Hansmann, Henry (1987), "Economic Theories of Nonprofit Organizations", in Walter Powell (org.), The Nonprofit Sector: A Research Handbook. New Haven: Yale University Press, 27-42.

Hodgson, Geoffrey (1999), Evolution and Institutions. On Evolutionary Economics and the Evolution of Economics. Cheltenham /Northampton: Edward Elgar.

Hollingsworth, Rogers; Boyer, Robert (1997), "Coordination of Economic Actors and Social Systems of Production”, in Rogers Hollingsworth; Robert Boyer (orgs.), Contemporary Capitalism. The Embeddedness of Institutions. Cambridge: Cambridge University Press, 1-47.

James, Estelle (1987), “The Nonprofit Sector in Comparative Perspective”, in Walter Powell (org.), The Nonprofit Sector: A Research Handbook. New Haven: Yale University Press, 397-415.

James, Estelle (1989), "The Private Provision of Public Services: A Comparison of Sweden and Holland", in Estelle James (org.), The Nonprofit Sector in International Perspective: Studies in Comparative Culture and Policy. Oxford: Oxford University Press: 31-59.

James, Estelle (1990), "Economic Theories of the Nonprofit Sector: A Comparative Perspective”, in Helmut Anheier; Wolfgang Seibel (orgs.), The Third Sector: Comparative Studies of Nonprofit Organizations. Berlin/New York: Walter de Gruyter, 21-30. Jeantet, Thierry (2003), A economia social europeia: em tudo a democracia. Lisboa: Poseidon.

Kingma, Bruce (2003), "Public Good Theories of the Nonprofit Sector: Weisbrod Revisited”, in Helmut Anheier; Avner Ben-Ner (orgs.), The Study of the Nonprofit Enterprise. New York: Kluwer Academic/Plenum Publishers, 53-65.

Kooiman, Jan (2003), Governing as Governance. London: Sage Publications.

Krashinsky, Michael (1986), "Transaction Costs and a Theory of the Nonprofit Organization”, in Susan Rose-Ackerman (org.), The Economics of Nonprofit Institutions: Studies in Structure and Policy. New York: Oxford University Press, 114-132. Ministério do Emprego e da Segurança Social (1992), Protocolo de Cooperação, policopiado.

Nyssens, Marthe (2000), "Les approches économiques du tiers secteur. Apports et limites des analyses anglo-saxonnes d'inspiration néo-classique”, Sociologie du Travail, 42(2000), 551-565. 
OECD (2003), The Nonprofit Sector in a Changing Economy. Bruxelas: OECD.

Olson, Mancur (1998), A lógica da ação coletiva: bens públicos e teoria dos grupos. Oeiras: Celta Editora [1. ${ }^{a}$ ed.: 1965].

Ortmann, Andreas; Schlesinger, Mark (2003), “Trust, Repute and the Role of Nonprofit Enterprise”, in Helmut Anheier; Avner Ben-Ner (orgs.), The Study of the Nonprofit Enterprise. New York: Kluwer Academic/Plenum Publishers, 77-114.

Reis, José (2007), A economia impura. Coimbra: Almedina.

Rose-Ackerman, Susan (org.) (1986), The Economics of Nonprofit Institutions. New York/Oxford: Oxford University Press.

Salamon, Lester; Anheier, Helmut (1998), "Social Origins of Civil Society: Explaining the Nonprofit Sector Cross-nationally”, Voluntas, 9(3), 213-248.

Weisbrod, Burton (1986), "Toward a Theory of the Voluntary Nonprofit Sector in

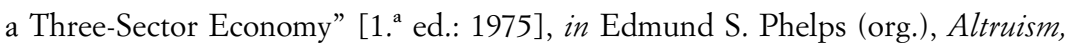
Morality and Economic Theory. New York: Russel Sage Foundation. Reimpresso em Susan Rose-Ackerman (org.), The Economics of Nonprofit Organizations: Studies in Structure and Policy. New York: Oxford University Press, 21-44.

Weisbrod, Burton (1988), The Nonprofit Economy. Cambridge (MA): Harvard University Press.

Williamson, Oliver (1985), The Economic Institutions of Capitalism. New York: The Free Pass. 